\title{
Involvement of Smad proteins in the differentiation of pancreatic AR42J cells induced by activin A
}

\author{
Y.-Q. Zhang, M. Kanzaki, M. Furukawa, H. Shibata, M. Ozeki, I. Kojima \\ Department of Cell Biology, Institute for Molecular and Cellular Regulation, Gunma University, Maebashi, Japan.
}

\section{Abstract}

Aims/hypothesis. Activin A induces differentiation of amylase-secreting pancreatic AR42J cells into endocrine cells. This study assesses the role of Smad proteins in the actions of activin A in AR42J cells.

Methods. The expression of Smad proteins was determined by northern blotting. Phosphorylation and translocation of Smad2 was measured by transfecting flag-tagged Smad2. Involvement of Smad2 was examined by transfecting cDNA encoding $\mathrm{N}$-terminal and C-terminal domains of Smad2.

Results. The mRNAs for Smad2 and Smad4 were abundantly expressed whereas the expression of mRNA for Smad1 and Smad3 was very low. Activin A induced serine-phosphorylation and the subsequent accumulation of the Smad2 in nuclei. Transfection of the N-terminal domain of Smad2, which acts as a dominantly negative mutant $(\operatorname{Smad} 2-\mathrm{N})$, blocked the morphological changes induced by activin A whereas the C-terminal domain of Smad2, which acts as a constitutively active mutant (Smad2-C), reproduced the activin-induced morphological changes. Similarly, Smad2-N blocked apoptosis induced by activin A and Smad2-C induced apoptosis. Activin A converted AR42J into insulin-secreting cells in the presence of hepatocyte growth factor and introduction of Smad2-N inhibited the differentiation. Smad2-C, however, did not induce differentiation in the presence of hepatocyte growth factor.

Conclusions/interpretation. Activation of the Smad2 pathway is necessary and sufficient to induce apoptosis and morphological changes. Although activation of the Smad2 pathway is required, it is not solely sufficient for the differentiation of AR42J into endocrine cells. [Diabetologia (1999) 42: 719-727]

Keywords Beta-cell, insulin, differentiation, activin A, Smad.
Pancreatic endocrine cells synthesize and secrete pancreatic hormones such as insulin, glucagon, somatostatin and pancreatic polypeptide. These cells resemble neuronal cells in many respects. For example,

Received: 15 October 1998 and in final revised form: 25 January 1999

Corresponding author: I. Kojima, M. D., Institute for Molecular and Cellular Regulation, Gunma University, Maebashi 371-8512, Japan

Abbreviations: Samd2-N, N-Terminal domain of Smad2; Smad2-C, C-terminal domain of Smad2; HGF, hepatocyte growth factor; RT-PCR, reverse transcription PCR; SSC, saline-sodium citrate buffer; MTT, 3-[4,5-dimethylthiazol-2-yl]2, 5-dithenyltetradium bromide. they have excitable membranes and express voltagedependent sodium channels, voltage-dependent calcium channels and ionotropic glutamate receptor channels $[1,2]$; they express many proteins typical of neurons including synaptophysin, neurofilaments, tyrosine hydroxylase and $\gamma$-amino butyric acid transporter [3, 4]; and, they extend neurites when cultured under appropriate conditions [5]. Nevertheless, they arise from epithelial cells originating from the endoderm $[3,5]$. Hence, pancreatic endoderm-derived progenitor cells differentiate into endocrine cells, which express many neuronal marker proteins.

Pancreatic AR42J cells are derived from a chemically induced pancreatic tumour and express both exocrine and neuroendocrine properties. These cells 
secrete amylase and express synaptophysin and neurofilaments [6]. Upon treatment with activin A, AR42J cells stop growing and their morphology changes considerably. Thus, they extend neurites [7]. The production of amylase is terminated and the expression of neuronal markers, including neurofilaments and synaptophysin, increases noticeably [7]. Furthermore, activin-treated cells express mRNA for glucose transporter-2, ATP-sensitive potassium channels and pancreatic polypeptide. Collectively, activin A converts AR42J cells into endocrine cells [7, 8]. Many of the activin-treated cells, however, eventually die by apoptosis unless an additional factor is added [9]. In the presence of either betacellulin [7] or hepatocyte growth factor [8], activin-treated AR42J cells survive and further convert to insulin-secreting cells. Since activin A acts as a differentiation factor during the development of islet cells [10], AR42J cells can provide a model system to study the molecular mechanism of differentiation induced by activin A in pancreatic progenitor cells.

The mechanism by which TGF- $\beta$ and related ligands exert their diverse effects has been studied intensively and the signal transduction pathways activated by these ligands have been described. It is now thought that Smad proteins are involved in the action of TGF- $\beta$ and related ligands [11-13]. Upon binding of the ligand to type II receptors, type I receptors are phosphorylated on the GS domain by type II receptor kinase leading to the activation of type I receptors. Activated type I receptors then phosphorylate cytoplasmic substrate proteins including pathway-restricted Smads (Smad2 and Smad3) at the C terminal domain. In unstimulated cells Smad2 and Smad3 exist as monomers. When stimulated, phosphorylated Smad2 or Smad3 or both form oligomeric complexes with Smad4 and then translocate into the nucleus [14]. These complexes then activate the transcription of target genes.

This study investigated the involvement of Smad proteins in the differentiation-induced activity of activin A in pancreatic AR42J cells.

\section{Materials and methods}

Materials. Recombinant human activin A was kindly provided by Y. Eto of Central Research Laboratory, Ajinomoto (Kawasaki, Japan). Recombinant human hepatocyte growth factor (HGF) was purchased from R\&D Systems (Minneapolis, Minn., USA). We obtained $\left[{ }^{3} \mathrm{H}\right]$ thymidine from Dupont-New England Nuclear (Boston, Mass., USA). Anti-Flag M2 mouse monoclonal antibody was purchased from Eastman Kodak (Scientific Imaging Systems, New Haven, Conn., USA). Antihuman amylase monoclonal antibody was purchased from Sigma Chemical (St. Louis, Mo., USA). Rabbit polyclonal antibody to phosphoserine was from Zymed Laboratories (San Francisco, Calif., USA). Polyclonal antibody against porcine insulin was provided by $\mathrm{K}$. Wakabayashi of the Institute for
Molecular and Cellular Regulation, Gunma University. Other commercially available antibodies were indocarbocyanineconjugated donkey anti-rabbit IgG, fluorescein (FITC)-conjugated donkey anti-mouse IgG (Jackson ImmunoResearch Laboratories, West Grove, Pa., USA), indocarbocyanine-conjugated donkey anti-guinea pig IgG (Cappel, Turnhout, Belgium).

RNA extraction and northern blot analysis. Total RNA was extracted from AR42J cells cultured with or without activin A and HGF at different time points using TRIzol Reagent (Gibco-BRL, Grand Island, N.Y., USA). Total cellular RNA $(20 \mu \mathrm{g})$ was denatured on a $1.2 \%$ agarose gel containing $2.2 \mathrm{~mol} / \mathrm{l}$ formaldehyde and blotted onto a nylon membrane (Hybond-N + , Amersham, Bucks, UK) by capillary blotting in $10 \times$ saline-sodium citrate buffer (SSC). The blot was hybridized with a $\left[{ }^{32} \mathrm{P}\right]$-labelled cDNA probe, and washed at a final stringency of $0.1 \times \mathrm{SSC}$ and $0.1 \%$ sodium dodecylsulphate (SDS) at $55^{\circ} \mathrm{C}$ for $30 \mathrm{~min}$ as described in detail elsewhere [15]. The probes for northern blot analysis were obtained by reverse transcription PCR (RT-PCR) of mRNA obtained from AR42J cells using primers based on the sequences of rat Smad1 [16], rat Smad3 [16], human Smad2 [17] and human DPC4 [18]. In some experiments, mRNA was extracted from rat hepatocytes as described before [14].

Cell culture and transfections. A subclone of AR42J cells [19], AR42J-B13 cells convert into insulin-producing cells after treatment with a combination of activin A and HGF. These were cultured in Dulbecco's modified Eagle's (DME) medium containing $20 \mathrm{mmol} / \mathrm{l} \mathrm{HEPES} / \mathrm{NaOH}$ (pH 7.4), $5 \mathrm{mmol} / \mathrm{l} \mathrm{NaH}-$ $\mathrm{CO}_{3}$ and $10 \% \mathrm{FCS}$ at $37^{\circ} \mathrm{C}$ under a humidified condition of $95 \%$ air and $5 \% \mathrm{CO}_{2}$. Transfection for immunofluorescence and immunoblotting was done using lipofectamine (Gibco/ BRL) according to the protocol of the manufacturer. The transfection efficiency was 20 to $40 \%$.

cDNA cloning. We identified Smad2 by RT-PCR from rat AR42J cells using a degenerated sense primer, 5 '-CAT(C)CAT(C)GAA(G)C(T)TG(C/A)AAA(G)G(C)CA-3' and an antisense primer, 5'-CCAG(A)CCC(T)TTC(G)ACA (G)AAT(C/G/A)C(G)A(T)CATA(T/C)CG(T)T(A/G)AT-3', which were based on regions of sequence similarity between the Drosophila Mad and C. elegans Sma genes, human Smad1 and mouse madr2. The $0.9-\mathrm{kb}$ insert of the Smad PCR product was then used as a probe in the screening of a rat brain cDNA library. Phages were plated to yield 40,000 plaques $/ 150 \mathrm{~mm}$ plate and incubated at $37^{\circ} \mathrm{C}$ for $12 \mathrm{~h}$ and then spotted in duplicate on nitrocellulose membranes. The hybridization was done at $37^{\circ} \mathrm{C}$ in $50 \%$ formamide, $10 \times$ Denhardt's solution, $5 \times \mathrm{SSPE}, 0.7 \%$ SDS, and $100 \mu \mathrm{g} / \mathrm{ml}$ of denatured salmon sperm DNA. The last wash was done with $2 \times$ SSC and $0.1 \%$ SDS. Several Mad-related clones were isolated and sequenced from both strands using an ABI PRISM Dye Terminator cycle Sequencing FS Ready Reaction Kit and Applied Biosystems DNA sequencer model 373S (ABI, Foster City, Calif., USA).

Generation of a flag epitope-tagged form of Smad2. To generate the N-terminal flag epitope-tagged Smad2, the N-terminal domain of Smad2 (Smad2-N) and the C-terminal domain of Smad2 (Smad2-C), an oligonucleotide containing the flag tag sequence (ACCACCATGGACTACAAAGACGATGACGACAAG) was used with another primer that was located around the initiation codon of rat Smad2 (ATGGACACAGGCTCTCCGG CTGAACTG) in high fidelity PCR (UITmaTM DNA polymerase, Perkin Elmer, Norwalk, Conn., USA) as the sense primers in the case of Smad 2 and 
Smad2-N. The antisense primer for Smad2 and Smad2-C was 5 '-TGACGGACTTTAGGACATGCTTGAGCATCCAC- $3{ }^{\prime}$. To generate the flag-tagged Smad2-N, a stop codon was added at amino acid 238 , and the antisense primer was 5 '-CTACTAACTTTGGTTCAACTGTTGGT CAC-3'. To generate the flag-epitope tagged Smad2-C, 247 amino acids of Smad2 were truncated by using a sense primer $5^{\prime}$ ACCACCATGGACTACAAAGACGATGACGACAAGCTGTCTCC TACCACTCTCTCCCCTGTC-3'. The PCR products were then confirmed by fully sequencing and cloned into the PCDNA3 expression vectors.

Immunoprecipitation and immunoblotting. We transiently transfected AR42J cells with expression constructs for flagSmad2, flag-Smad2-N and flag-Smad2-C, respectively, using lipofectamine. The medium was changed $24 \mathrm{~h}$ after transfection into serum-free medium and cells were incubated for another $4 \mathrm{~h}$. Then, the medium was changed again to fresh medium and cells were incubated in the presence or absence of activin A. Cells were washed, scraped and solubilized in a buffer containing $20 \mathrm{mmol} / \mathrm{l}$ TRIS-HCl (pH 7.5), $150 \mathrm{mmol} / \mathrm{l} \mathrm{NaCl}$, $2 \%(\mathrm{v} / \mathrm{v})$ Triton X-100, $1 \mathrm{mmol} / \mathrm{l}$ phenylmethyl sulphonyl fluoride (PMSF), $2 \mathrm{mmol} / \mathrm{l}$ sodium vanadate, $4 \times 10^{-7} \mathrm{~mol} / \mathrm{l}$ leupeptin, $3 \times 10^{-7} \mathrm{~mol} / \mathrm{l}$ pepstatin followed by sonication for $15 \mathrm{~s}$. Then cell lysates were pelleted by centrifugation and subjected to immunoprecipitation with anti-flag M2 affinity gel (Scientific Imaging Systems, Eastman Kodak). Immunoprecipitates were separated by $10 \%$ SDS-polyacryalmide gel electrophoresis (SDS-PAGE), then samples were transferred to PVDF membranes (Immobilon P, Milli-pore Japan, Tokyo, Japan) followed by immunoblotting with mouse anti-flag M2 monoclonal antibody and rabbit polyclonal antibody to phosphoserine, respectively, and developed using an enhanced chemiluminescence detection system (Amersham) as recommended by the manufacturer.

Determination of cell viability and DNA fragmentation. The viability of AR42J cells transfected with Smad2-C and mock vectors was determined using MTT, 3-[4, 5-dimethylthiazol-2-yl]2, 5-dithenyltetradium bromide (Sigma). In brief, MTT solution was added to cells $(0.5 \mathrm{mg} / \mathrm{ml})$ and after $3 \mathrm{~h}$ of incubation at $37^{\circ} \mathrm{C}$ the reaction was stopped by adding $0.04 \mathrm{~N} \mathrm{HCl}$ of isopropanol. Absorbance was measured at a wavelength of 595 $\mathrm{nm}$. The results are expressed as means \pm SEM and statistical analysis was carried out using Student's $t$ test. Differences of $p<0.05$ were considered to be significant.

For the measurement of DNA fragmentation, cells were collected by centrifugation and lysed by incubation for $3 \mathrm{~h}$ at $50^{\circ} \mathrm{C}$ in lysis buffer $(10 \mathrm{mmol} / 1$ EDTA, $10 \mathrm{mmol} / 1$ TRIS $(\mathrm{pH}$ $8.0), 0.5 \%$ sodium dodecyl sulphate (SDS) and $0.15 \mathrm{mg} / \mathrm{ml}$ proteinase K). Next we added RNase A $(0.5 \mathrm{mg} / \mathrm{ml})$ and then incubated lysates for an additional hour. We electrophoresed DNA in a $1.8 \%$ agarose gel stained with ethidium bromide and made them visible by exposing them to ultraviolet light as described in detail elsewhere [20].

Immunofluorescence study. Cells were cultured on non-coated glass coverslips at a density of $2 \times 10^{5}$ cells $/ 35 \mathrm{~mm}$ dish and transiently transfected with Smad2, Smad2-N and Smad2-C, respectively. Cells were washed and fresh medium was added. Activin A or activin A plus HGF was added according to the experimental protocol. Cells were washed and fixed $48 \mathrm{~h}$ later with $4 \%$ paraformaldehyde in PBS, permeabilized with PBS containing $0.1 \%$ ( $\mathrm{vol} / \mathrm{vol}$ ) Triton X-100 and incubated sequentially with Blocking Ace (Morinaga, Tokyo, Japan). Cells were then incubated with primary antibodies at room temperature for $60 \mathrm{~min}$, extensively rinsed in TBST $(0.15 \mathrm{~mol} / \mathrm{l} \mathrm{NaCl}$,
$0.02 \mathrm{~mol} / \mathrm{l}$ TRIS-HCl (pH 7.4), $0.1 \%$ Tween-20) and exposed to secondary fluorescent antibodies at room temperature for $40 \mathrm{~min}$. Images were obtained using a Zeiss microscope equipped with fluorescein and rhodamine filter sets (Axiophoto, Carl Zeiss, Thornwood, N. Y., USA). For the observation of subcellular localization of Smad2 in AR42J cells, a confocal laser microscope (Bio-Rad Labs, Richmond, Calif., USA) was used.

\section{Results}

Cloning of rat Smad2. To identify rat Smad homologues, we screened a rat brain library with a probe made from RT-PCR using a degenerated primer based on regions of sequence similarity between the Drosophila Mad, C. elegans Sma genes, human Smad1 and mouse madr2. We obtained several independent clones and determined the sequences from both strands. We determined the full length insert of $1.9 \mathrm{~kb}$ rat Smad2 cDNA clone, which contains an open reading frame that is predicted to encode a protein of 467 amino acids (DDBT/EMBL/GenBank nucleotide sequence data base accession number AB017912). Rat Smad2 amino acid sequences share 99.6\% identity with mouse Smad2 [21] and 99.4\% identity with human Smad2 [17]. Its nucleotide sequence shares $95.4 \%$ identity with mouse Smad2 [20], and 91.3\% identity with human Smad2 [17] (Fig.1). Comparison of the amino acid sequence of rat Smad2 with rat Smad1 and rat Smad3 showed $54.8 \%$ and $89.2 \%$ homologies, respectively [16], and the nucleotide sequence comparison shows $48.8 \%$ and $69.7 \%$ homologies, respectively.

mRNA expression of Smad in AR42J cells. The expression of Smad1, 2, 3 and 4 in AR42J cells was investigated by northern blot analysis (Fig. 2A). The results show that expressions of Smad2 and Smad4 were abundant whereas Smad1 and Smad3 were much less expressed. Note that Smad3 mRNA required longer exposure to the gels to be detected. The expression pattern of Smads in AR42J cells was different from that in rat hepatocytes. We then investigated whether or not the mRNA for Smad2 and Smad4 changed during the differentiation of AR42J into insulin-secreting cells. We treated AR42J cells with activin A and HGF for $72 \mathrm{~h}$. There were no changes in the expression of Smad2 and Smad4 before or after differentiation into insulin-secreting cells (Fig. 2B).

Ligand-induced phosphorylation and nuclear accumulation of Smad2. It has been shown that Smad proteins are phosphorylated in the cytoplasm and translocate to the nucleus upon stimulation with ligands [9]. To see if activin A activates the Smad pathway in AR42J cells, we examined whether or not Smad2 is phosphorylated and then translocated into nuclei in 


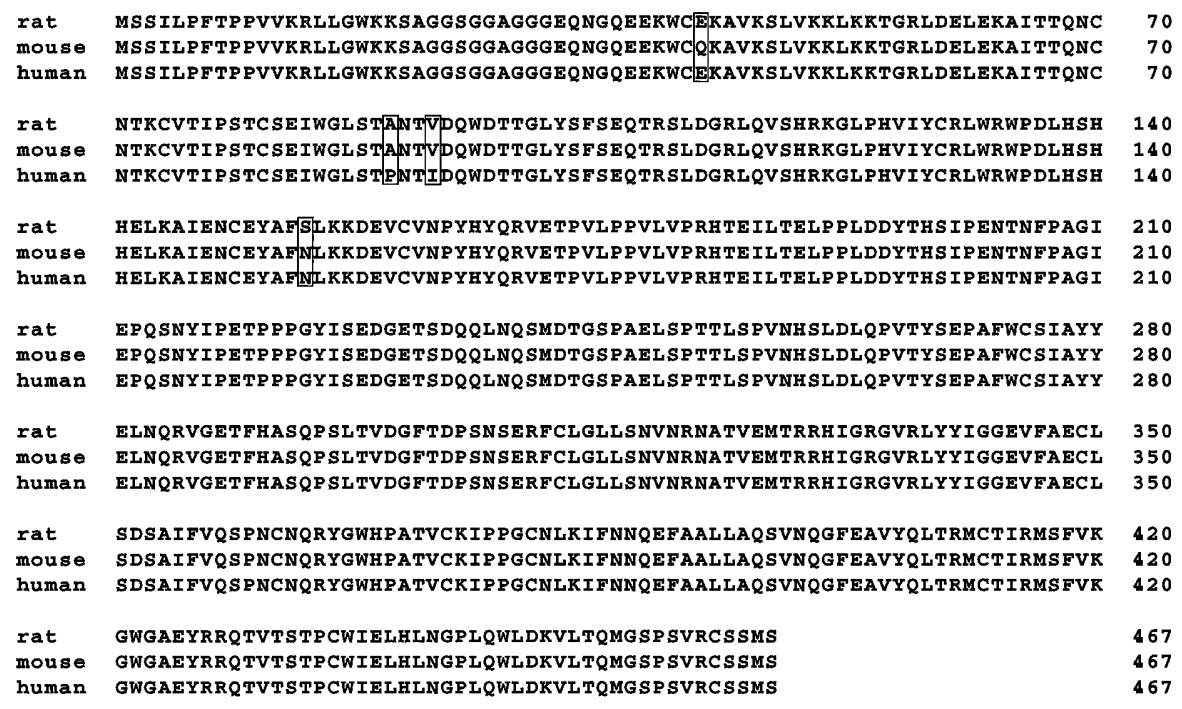

Fig.1. Comparison of amino acid sequence of rat $\mathrm{Smad} 2$ with human and mouse Smad2. The amino acid residues that are different are highlighted in boxes and the positions of the amino acids residues are labelled on the right

Table 1. Effect of transfection of Smad2-N and Smad2-C on the morphology of AR42J cells

\begin{tabular}{llcc}
\hline $\begin{array}{l}\text { Transfected } \\
\text { gene }\end{array}$ & $\begin{array}{l}\text { Number of } \\
\text { transfected } \\
\text { cells }\end{array}$ & Shape-changed & $\begin{array}{l}\text { Shape- } \\
\text { unchanged }\end{array}$ \\
\hline Smad2-N & 784 & $52(6.6 \%)$ & $732(93.4 \%)$ \\
Smad2-C & 806 & $739(91.7 \%)$ & $67(8.3 \%)$ \\
\hline
\end{tabular}

AR42J cells were transfected with flag-tagged Smad2-N or Smad2-C and incubated for $48 \mathrm{~h}$. Activin A ( $\mathrm{nmol} / \mathrm{l})$ was added for Smad2-N-transfected cells. Effectively transfected cells were identified by staining with anti-flag antibody. Morphological changes in effectively transfected cells were analysed. The results were accumulated data from five to six experiments. Note that $93 \%$ of the untransfected cells changed their shape by activin treatment

response to activin A. Cells were transiently transfected with flag-Smad2, incubated for $24 \mathrm{~h}$ and then exposed to activin A for $30 \mathrm{~min}$. Cells were subsequently lysed and subjected to immunoprecipitation with antiflag M2 antibody and then immunoblotted with antiphosphoserine antibody. In the absence of the ligand in AR42J cells Smad2 was not appreciably phosphorylated, whereas notable phosphorylation was observed after the addition of activin A (Fig. 3A). The subcellular localization of Smad2 in AR42J cells was analysed by measuring immunofluorescence using the anti-flag antibody in the presence or absence of the ligand. In the absence of the ligand, Smad2-specific staining was predominant in the cytoplasm of the cells. After stimulation with activin $\mathrm{A}$ for $1 \mathrm{~h}$, the staining was concentrated in the nucleus (Fig. 3B). Thus activin $\mathrm{A}$ induced the translocation of Smad2 from the cytoplasm to the nucleus in AR42J cells.
Effect of transfection of Smad2-N and Smad2-C on the action of activin $A$. The results above indicate that activin A activates the Smad pathway in AR42J cells, and presumably Smad2 is involved. To investigate the role of the Smad pathway in the action of activin A in AR42J cells, we transfected the cells with dominantly negative and constitutively active mutants of Smad2. It is known that the N-terminal domain of Smad2 (Smad2-N) inhibits signalling through Smad2, whereas the C-terminal domain of Smad2 (Smad2-C) activates the Smad pathway in the absence of the ligand. Thus, Smad2-N and Smad2-C act as dominantly negative and constitutively active mutants, respectively [22-23]. We transiently transfected AR42J cells with Smad2-N or Smad2-C and examined whether or not these mutants affected cellular functions. To identify cells effectively transfected, we measured the immunofluorescence using anti-flag antibody.

Activin A induced the morphological changes in AR42J cells. Activin-treated cells extend neuritelike processes [6]; untransfected cells extended processes in response to activin A (Fig.4). In contrast, in cells effectively transfected with Smad2-N, activin A did not induce morphological changes (Fig. 4 and Table 1). Conversely, when cells were effectively transfected with Smad2-C, a constitutively active form of Smad2, they extended neurite-like processes (Fig. 5 and Table 1). Activin A did not only induce morphological changes but also eventually induced cell death by apoptosis [9]. Transfection of Smad2-N prevented activin-induced cell death (data not shown). Conversely, transfection of Smad2-C induced cell death in AR42J cells. Transfection of Smad2-C, but not Smad2-N, reduced the viability of the cells (Fig.6A). Note that the efficiency of transfection was 20 to $40 \%$. In addition, DNA ladder formation was observed in Smad2-C-transfected but not in mock-transfected cells (Fig.6B). A combination of activin $\mathrm{A}$ and HGF induces differentiation of 

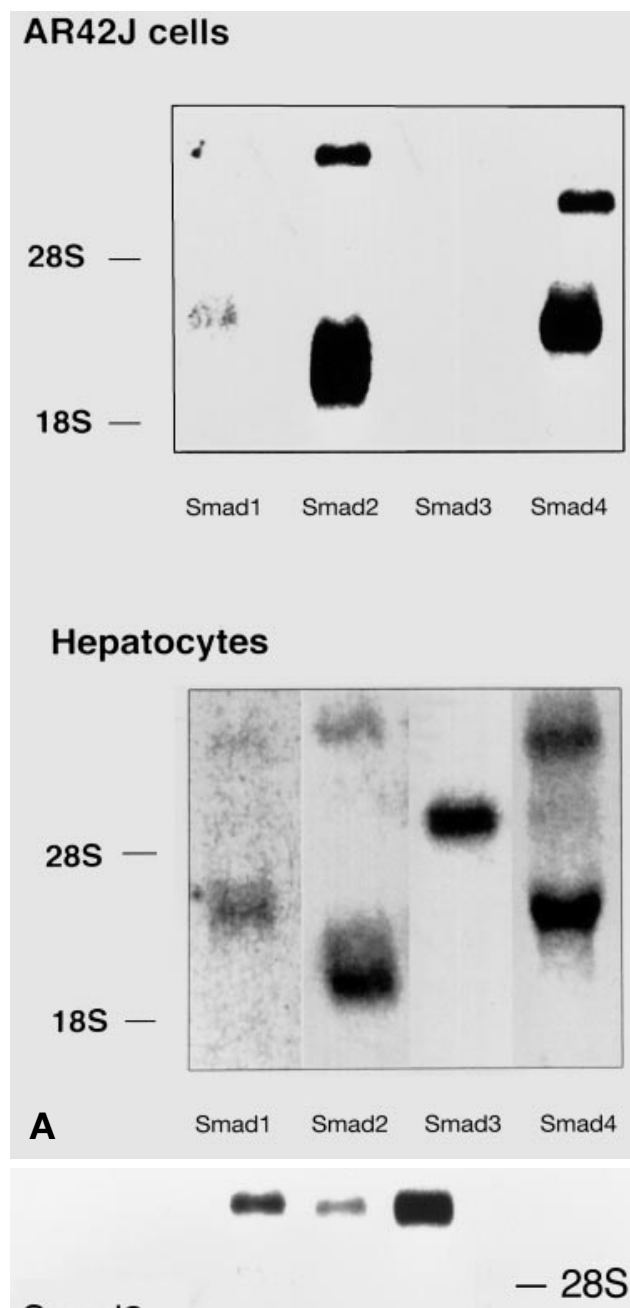

Smad2
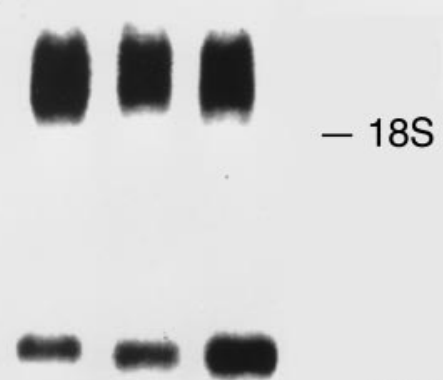

$-28 S$

Smad4

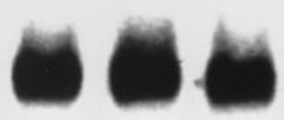

$-18 S$

G3PDH

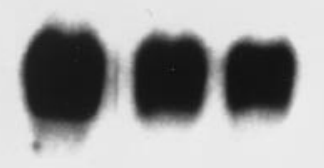

B $\quad \begin{aligned} & \text { time } \\ & (\mathrm{hr})\end{aligned}$

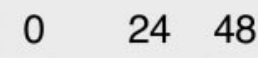

Table 2. Effect of transfection of Smad2-N and Smad2-C on the differention of AR42J into insulin-producing cells

\begin{tabular}{llll}
\hline $\begin{array}{l}\text { Transfected } \\
\text { gene }\end{array}$ & $\begin{array}{l}\text { Number of } \\
\text { transfected } \\
\text { cells }\end{array}$ & $\begin{array}{l}\text { Insulin- } \\
\text { positive cells }\end{array}$ & $\begin{array}{l}\text { Insulin- } \\
\text { negative cells }\end{array}$ \\
\hline Smad2-N & 788 & $55(7.0 \%)$ & $733(93.0 \%)$ \\
Smad2-C & 758 & $23(3.0 \%)$ & $735(97.0 \%)$ \\
\hline
\end{tabular}

AR42J cells were transfected with flag-tagged Smad2-N or Smad2-C or Smad2-C and incubated for $72 \mathrm{~h}$ with $100 \mathrm{pmol} / \mathrm{l}$ HGF. Activin A (2 nmol/l) was also added for Smad2-N-transfected cells. Cells were stained with anti-insulin and anti-flag antibodies. Number of insulin-positive cells among effectively transfected cells was counted. Results are the accumulated data from five experiments. Note that $91 \%$ of the untransfected cell converted to insulin-positive cells by activin $\mathrm{A}$ and $\mathrm{HGF}$

AR42J into insulin-producing cells [7]. To assess the role of the Smad pathway in this process, AR42J cells were transfected with Smad2-N and were then incubated with activin A and HGF. Effectively transfected cells were identified by the expression of flag. Treatment of the untransfected cells with a combination of activin $\mathrm{A}$ and HGF led to the expression of insulin (Fig. 7). In Smad2-N-transfected cells, HGF and activin A did not induce differentiation (Fig. 7 and Table 2). We then transfected AR42J cells with Smad2C. Transfection of Smad2-C, however, did not convert AR42J to insulin-producing cells even in the presence of HGF (Fig. 8 and Table 2). This result suggests the possibility that another signal(s) other than the activation of Smad2 is necessary for inducing differentiation. To test this possibility, we incubated cells transfected with Smad2-C with a low dose of activin A, which by itself does not induce differentiation. Cells transfected with Smad2-C converted into insulin-producing cells when $0.1 \mathrm{nmol} / \mathrm{l}$ activin A was added together with HGF (Fig. 9). Note that at this concentration, activin A did not convert untransfected AR42J into insulin-secreting cells (Fig. 9 and Table 3). Thus, introduction of Smad2-C enabled the low concentration of activin A to induce differentiation.

\section{Discussion}

We investigated the role of Smad proteins in activininduced differentiation of AR42J cells, which resem-

Fig. 2 A, B. Total RNA was extracted from AR42J cells and rat hepatocytes and mRNA expression of Smad proteins was determined by northern blotting $(\mathbf{A})$. The blot is representative for three similar experiments. Total RNA was extracted from AR42J cells before and $24 \mathrm{~h}$ and $48 \mathrm{~h}$ after treatment with 2 $\mathrm{nmol} / \mathrm{l}$ activin A and $100 \mathrm{pmol} / \mathrm{l} \mathrm{HGF}$ (B). Expression of mRNA for Smad2 and Smad4 was measured by northern blotting. The blot is representative for three similar experiments 


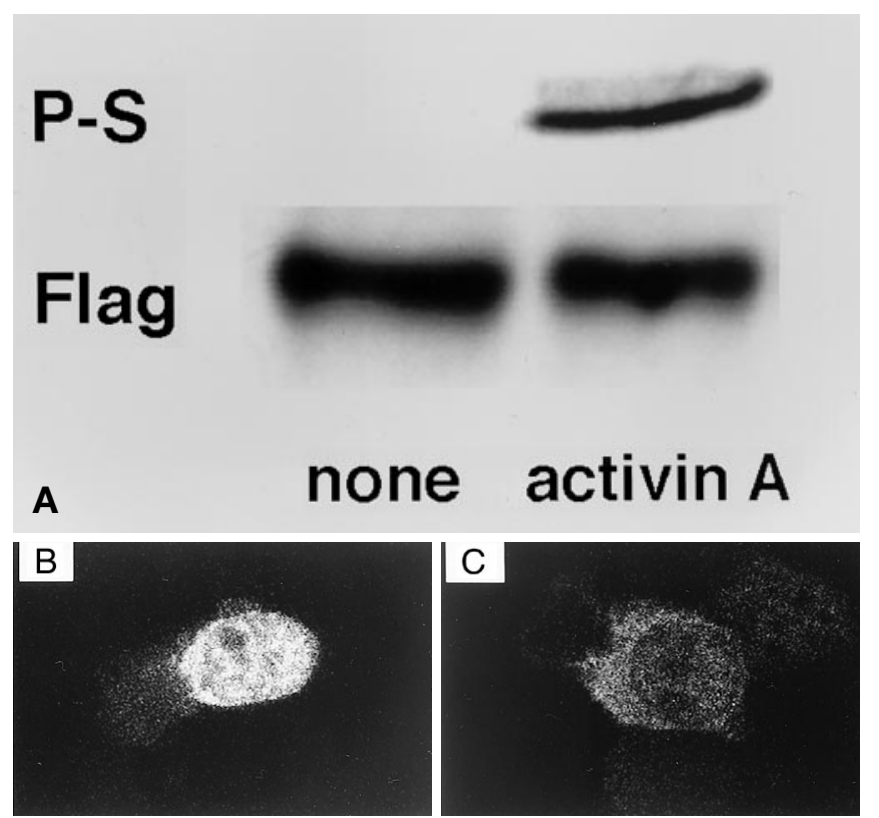

Fig.3 A-C. AR42J cells transfected with flag-tagged Smad2 were incubated for $30 \mathrm{~min}$ with $2 \mathrm{nmol} / \mathrm{l}$ activin A (A). Cells were lysed and the lysates were immunoprecipitated by antiflag antibody. The precipitated proteins were separated by SDS-PAGE, followed by western blotting by anti-flag (Flag) and anti-phosphoserine (PS) antibodies. The result is representative for four similar experiments. AR42J cells transfected with flag-tagged Smad 2 were incubated for $60 \mathrm{~min}$ with $(\mathbf{B})$ or without (C) $2 \mathrm{nmol} / \mathrm{l}$ activin A. Cells were fixed and immunohistochemistry was done with confocal microscopy using an anti-flag antibody. The result is representative for four similar experiments

Table 3. Effect of transfection of Smad2-C in the presence of low concentration of activin A

\begin{tabular}{llll}
\hline Transfection & $\begin{array}{l}\text { Number } \\
\text { of cells }\end{array}$ & $\begin{array}{l}\text { Insulin-positive } \\
\text { cells (\%) }\end{array}$ & $\begin{array}{l}\text { Insulin-negative } \\
\text { cells (\%) }\end{array}$ \\
\hline Transfected cells & 289 & $88.6 \%$ & $11.4 \%$ \\
Untransfected cells & 243 & $3.2 \%$ & $96.8 \%$
\end{tabular}

AR42J cells transfected with Smad2-C were incubated for $72 \mathrm{~h}$ with $100 \mathrm{pmol} / 1 \mathrm{HGF}$ and $100 \mathrm{pmol} / \mathrm{l}$ activin A. Cells were double-stained with anti-flag and anti-insulin antibodies and the number of insulin-positive cells were counted. Results were obtained from two experiments

ble progenitor cells of the pancreas in many respects. Among various Smad proteins, Smad2 and Smad4 were expressed predominantly in AR42J cells. If Smad proteins mediate the effect of activin A, Smad2 and Smad 4 are the most likely candidates as mediators of the activin action in these cells. The expression was not changed substantially during differentiation into insulin-producing cells. Proteins Smad 2 or Smad3 or both are activated by TGF- $\beta$ and activin A by phosphorylation and form oligomeric complexes with Smad4 [21, 24]. Then the oligomeric complexes translocate into the nuclei and activate the transcription of
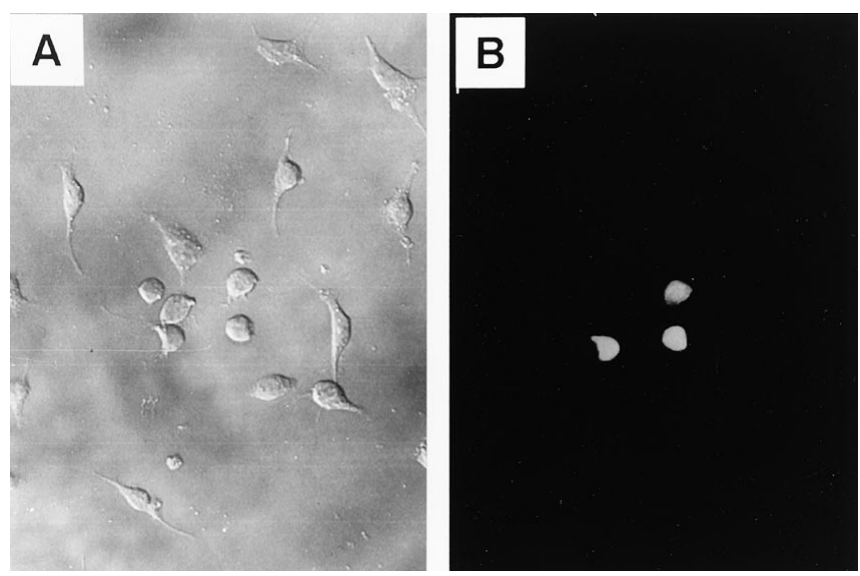

Fig. 4A, B. Nomarski image (A). AR42J cells transfected with flag-tagged Smad2-N were incubated for $48 \mathrm{~h}$ with $2 \mathrm{nmol} / \mathrm{l} \mathrm{ac}-$ tivin A. Immunohistochemistry was performed using anti-flag antibody (B)
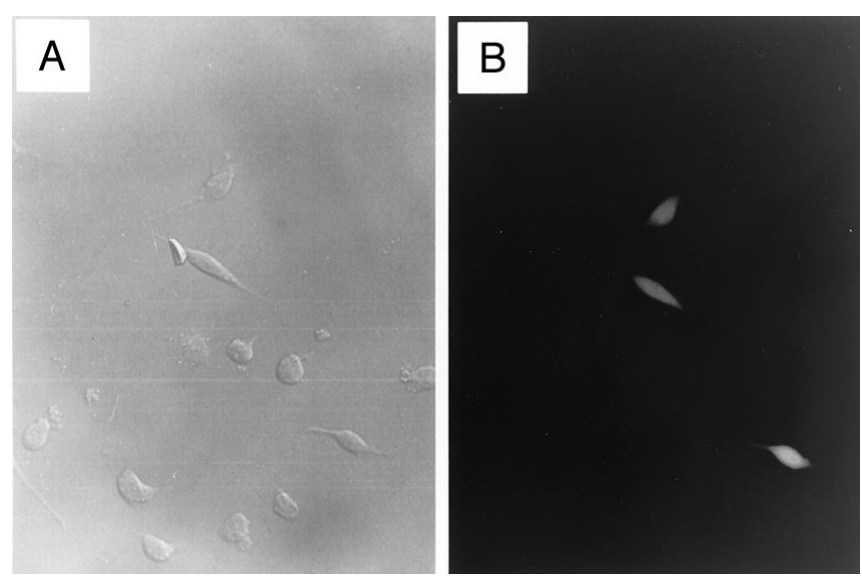

Fig.5A, B. Nomarski image (A). AR42J cells transfected with flag-tagged Smad2-C were incubated for $48 \mathrm{~h}$ and immunohistochemistry was performed using anti-flag antibody (B)

target genes [11-13]. As regards activin signalling, type I activin receptors are shown to phosphorylate the C-terminal region of Smad2 and activate Smad2 [20]. In agreement with this notion, Smad2 was phosphorylated at its serine residue and subsequently accumulated in the nucleus in response to activin A. Although we did not examine whether or not Smad2 formed a complex with Smad4, the present results together with previous reports [11-13] suggest that upon stimulation by activin A, Smad2 and presumably endogenous Smad4 are phosphorylated and form oligomeric complexes in AR42J cells. Alternatively, Smad 2 may form homomeric trimers and then translocate into the nucleus [24].

The Smad proteins consist of the N-domain, C-domain and the linker domain which connects the $\mathrm{N}$-domains and $\mathrm{C}$-domains. The $\mathrm{C}$-domain is thought to be an active domain and its activity is inhibited by the $\mathrm{N}$-domain. Type I receptors phosphorylate the C-do- 


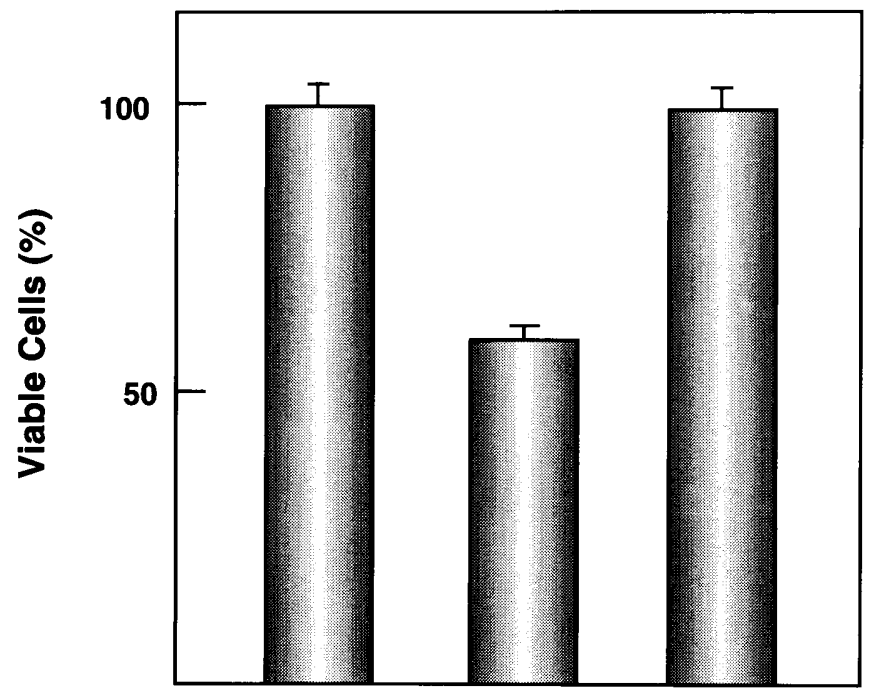

A Mock Smad2-C Smad2-N
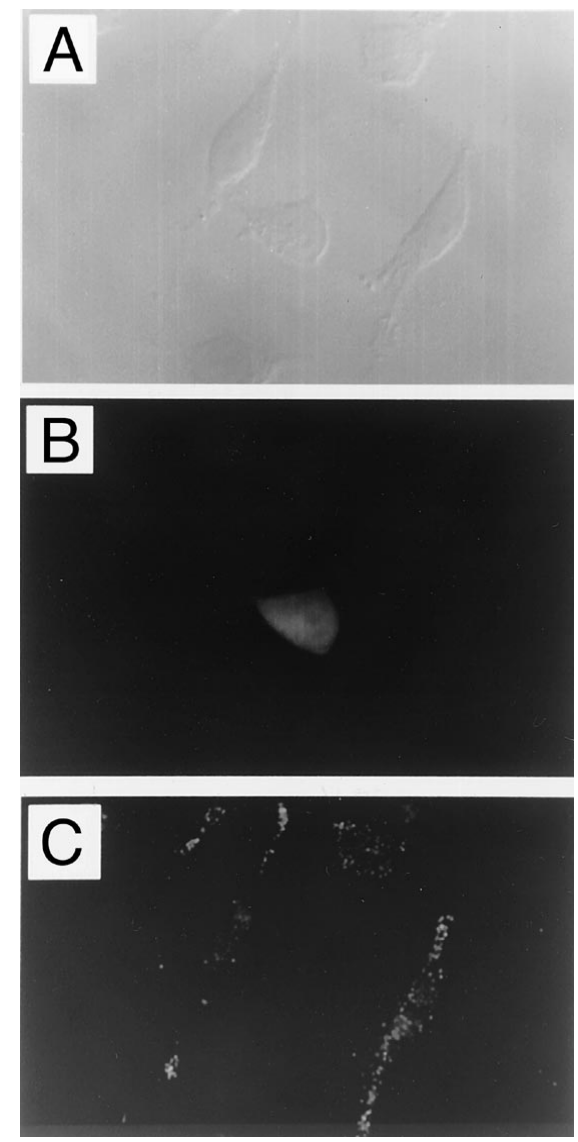

Fig. 7A-C. AR42J cells transfected with flag-tagged Smad2-N were incubated for $72 \mathrm{~h}$ with $2 \mathrm{nmol} / \mathrm{l}$ activin A and $100 \mathrm{pmol} / \mathrm{l}$ HGF. Cells were then double-stained with anti-flag and antiinsulin antibodies. (A) Nomarski image. (B) Cells stained with anti-flag antibody. (C) Cells stained with anti-insulin antibody

Smad2-N seems to block the growth inhibitory effect of activin A whereas transfection of Smad2-C mimics the effect of activin $\mathrm{A}$ in hepatocytes (unpublished observation). Our results indicate that transfection of Smad2-N inhibits activin A action in AR42J cells by inducing morphological changes and differentiation into endocrine cells. On the other hand, Smad2-C induced morphological changes and apoptosis. Hence, activation of the Smad2 pathway is necessary and sufficient for the induction of morphological changes and apoptosis. In contrast, activin-induced differentiation of AR42J into insulin-producing cells was blocked by Smad2-N, whereas Smad2-C could not reproduce the effect of activin A. We interpret these data to mean that the Smad2 pathway is necessary, but not sufficient, for the effect of activin A on the differentiation of AR42J into insulin-secreting cells. Presumably, an additional signal is necessary for the conversion of AR42J into endocrine cells induced by activin A. This notion is supported by the observation that a low dose of activin A, which did not convert AR42J to insulin-producing cells, did induce differentiation main and this phosphorylation is thought to relieve suppression by the $\mathrm{N}$-domain [11-13]. Consequently, the $\mathrm{N}$-domain functions as a dominantly negative regulator of Smad2, whereas the C-domain acts as a constitutively active form of Smad2. Transfection of 

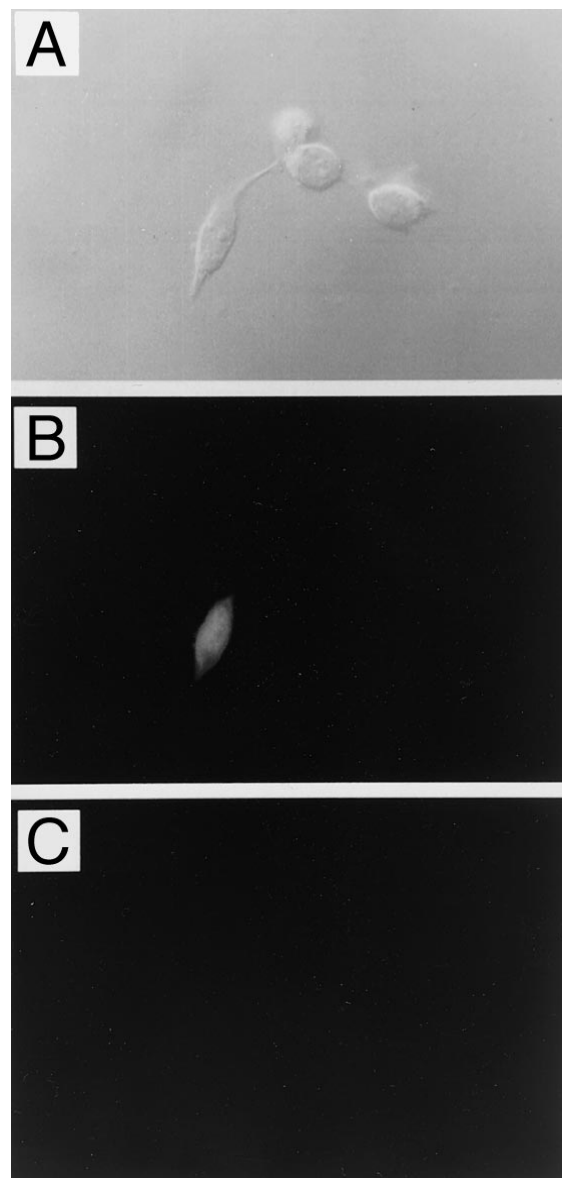

Fig.8 A-C. AR42J cells transfected with Smad2-C were incubated for $72 \mathrm{~h}$ with $100 \mathrm{pmol} / \mathrm{lHGF}$. Cells were then doublestained with anti-flag and anti-insulin antibodies. (A) Nomarski image. (B) Cells were stained with anti-flag antibody. (C) Cells were stained with anti-insulin antibody

when Smad2-C was introduced. Presumably, a low dose of activin A generated an additional signal, which together with the Smad2 pathway caused differentiation. In this regard, we recently observed that the conversion of AR42J into insulin-producing cells by activin A and HGF was blocked by SB203580, an inhibitor of p38 mitogen-activated protein kinase (unpublished observation). Since the effect of HGF was not blocked by SB203580, it is possible that the other intracellular signal responsible for the activin-induced differentiation is the p38 MAP kinase pathway. Further study is necessary to clarify this point.

In summary, activin A activates the Smad2 pathway in AR42J cells. Changes in morphology and apoptosis induced by activin A are mediated solely by the Smad2 pathway. But activin-mediated differentiation into endocrine cells requires the activation of Smad2 and possibly another intracellular signal.

Acknowledgements. This study was supported by a Grant-inAid from The Ministry of Education, Science, Sports and Cul-
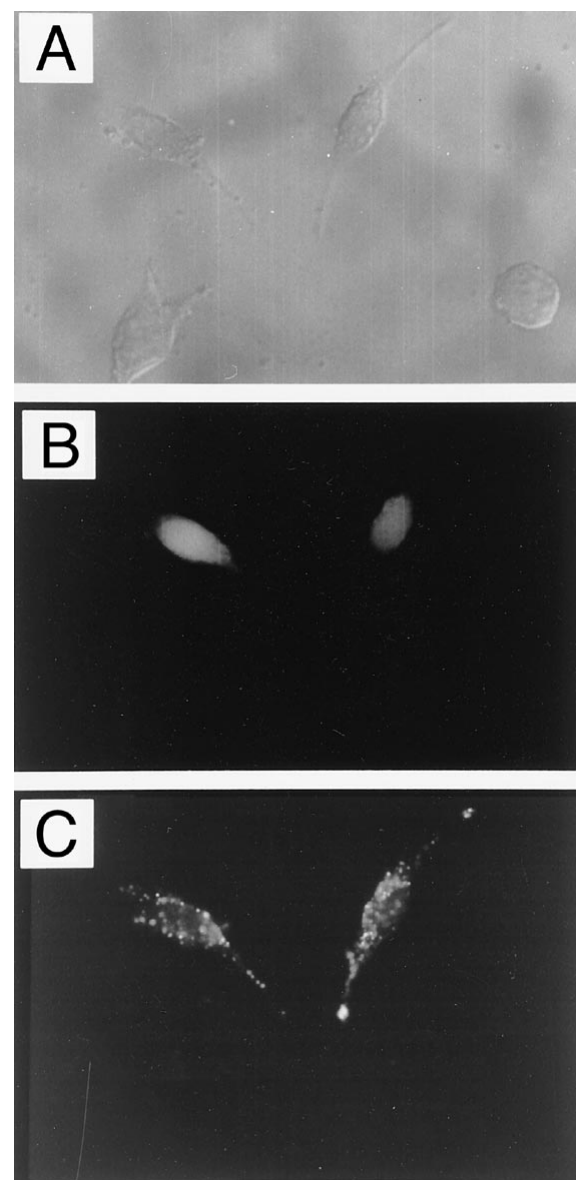

Fig.9A-C. AR42J cells transfected with Smad2-C were incubated for $72 \mathrm{~h}$ with $100 \mathrm{pmol} / \mathrm{l} \mathrm{HGF}$ and $100 \mathrm{pmol} / \mathrm{l}$ activin A. Cells were then double-stained with anti-flag and anti-insulin antibodies. (A) Normarski image. (B) Cells were stained with anti-flag antibody. (C) Cells were stained with anti-insulin antibody

ture of Japan and grants from The Japanese Pancreatic Foundation, The Japanese Diabetes Foundation, The Novartis Foundation of Japan, The Uehara Foundation, The Life Science Foundation and The Yamanouchi Foundation for Research on Metabolic Disorders. Authors are grateful to M. Odagiri, M. Ozeki and T. Tajima for assistance.

\section{References}

1. Aschcroft FM, Rorsman P (1989) Electrophysiology of the pancreatic beta-cells. Prog Biophys Molec Biol 54: 87-143

2. Gonoi T, Mizuno N, Inagaki N et al. (1994) Functional neuronal ionotropic glutamate receptors are expressed in the non-neuronal cell line MIN6. J Biol Chem 269: 16989-16992

3. Alpert S, Hanahan D, Teitelman G (1988) Hydrid insulin genes reveal a developmental lineage for pancreatic endocrine cells and imply a relationship with neurons. Cell 53: 295-308

4. Reats A, Solimena M, Matteoli M, Folli F, Takei K, Camilli PD (1991) GABA and pancreatic $\beta$-cells: colocalization of glutamic acid decarboxylase and GABA with synaptic-like 
microvesicels suggests their role in GABA storage and secretion. EMBO J 10: 1275-1284

5. Teitelman G (1990) Insulin cells of pancreas extend neurites but do not arise from the neuroectoderm. Dev Biol 142: 368-379

6. Christophe J (1994) Pancreatic tumor cell line AR42J: an amphicrine model. Am J Physiol 266: G963-G971

7. Ohnishi H, Ohgushi N, Tanaka S et al. (1995) Conversion of amylase-secreting rat pancreatic AR42J cells to neuronlike cells by activin A. J Clin Invest 95: 2304-2314

8. Mashima H, Ohnishi H, Wakabayashi K et al. (1996) Betacellulin and activin A coordinately convert amylase-secreting pancreatic AR42J cells into insulin-secreting cells. J Clin Invest 97: 1647-1654

9. Furukawa M, Zhang YQ, Nie L, Shibata H, Kojima I (1999) Role of Mitogen-activated protein kinase and phosphoinositide 3-kinase in the differentiation of AR42J cells induced by hepatocytes growth factor. Diabetologia 42: 450-456

10. Miralles F, Czernichow P, Sharfmaun R (1998) Follistatin regulates the relative proportions of endocrine versus exocrine tissue during pancreatic development. Development 125: 1017-1024

11. Massague J, Hata A, Liu F (1997) TGF- $\beta$ signalling through the Smad pathway. Trends Cell Biol 7: 187-192

12. Heldin CH, Miyazono K, Dijke P (1997) TGF- $\beta$ signalling from cell membrane to nucleus through SMAD proteins. Nature 390: 465-471

13. Hu PPI, Datto MB, Wang XF (1998) Molecular mechanism of transforming growth factor $\beta$ signalling. Endocr Rev 19: 349-363

14. Kawabata M, Inoue H, Hanyu A, Imamura T, Miyazono K (1998) Smad proteins exist as monomers in vivo and undergo homo- and hetero-oligomerization upon activation by serine/threonine kinase receptors EMBO J 17: 4056-4065

15. Zhang YQ, Kanzaki M, Shibata H, Kojima I (1997) Regulation of the expression of follistatin in rat hepatocytes. Biochim Biophys Acta 1354: 204-210

16. Chen Y, Lebrun JJ, Vale W (1996) Regulation of transforming growth factor $\beta$ - and activin-induced transcription by mammalian Mad proteins. Proc Natl Acad Sci USA 93: 12992-12997

17. Riggins GJ, Thiagalin S, Rozenblum E et al. (1996) Madrelated genes in the human. Nat Genet 13: 347-349

18. Hahn SA, Schutte M, Hoque ATMS et al. (1996) DPC4, a candidate tumor suppressor gene at human chromosome 18q21.1. Science 271: 350-353

19. Mashima H, Shibata H, Mine T, Kojima I (1996) Formation of insulin-secreting cells from pancreatic AR42J cells by hepatocyte growth factor. Endocrinology 137: 3969-3976

20. Zhang YQ, Kanzaki M, Mashima H, Mine T, Kojima I (1996) Norepinephrine reverses the effect of activin A on DNA synthesis and apoptosis in cultured rat hepatocytes. Hepatology 23: 288-293

21. Lagna G, Hata A, Hemmati-Brivanlou A, Massague J (1996) Partnership between DPC and SMAD proteins in TGF- $\beta$ signalling pathways. Nature 383: 832-836

22. Hata A, Lo RS, Wotton D, Lagna G, Massague J (1997) Mutations increasing autoinhibition inactivate tumor suppressors Smad2 and Smad4. Nature 388: 82-87

23. Baker J, Harland RM (1996) A novel mesoderm inducer, Madr2, functions in the activin signal transduction pathway. Genes Dev 10: 1880-1889

24. Macias-Silva M, Abdolla S, Hoodless PA, Pirone R, Attisano L, Wrana JL (1996) MADR2 is a substrate of the TGF- $\beta$ receptor and its phosphorylation is required for nuclear accumulation signaling. Cell 87: 1215-1224 